\title{
La regulación del procedimiento administrativo en América Latina con ocasión de la primera década (2001-2011) de la Ley de Procedimiento Administrativo General del Perú (ley 27444)
}

\section{Administrative procedure regulation in Latin America, first decade of General Administrative Procedure Law in Peru (Law No. 27444, 2001-2011)}

\author{
ALLAN R. BREWER-CARÍAS*
}

Resumen: La codificación del procedimiento administrativo es el signo más importante de la evolución del derecho administrativo en América Latina, pues con estas normas se comenzó a regular con mayor amplitud y precisión la actividad de la administración pública, tanto en sus aspectos sustantivos como en los referidos a su relación con los administrados. El presente artículo analiza la regulación brindada al procedimiento administrativo en diversos países de Latinoamérica, enfatizando en la ley 27444 del Procedimiento Administrativo General del Perú.

Palabras clave: Procedimiento administrativo - principios - administración pública - administrado

Abstract: Codification of the administrative procedure is the most important sign of evolution in administrative law in Latin America. With these rules, began the regulation of Public Administration activity with more accuracy in a wider range, both in its substantial aspects and in relationship with applicants. This article analyses regulation provided to the administrative procedure in several countries of Latin America, emphasizing on Peruvian Law No. 27444 from General Administrative Procedure.

Key words: Administrative Procedure - principles - Public Administration applicant

* Es profesor de la Universidad Central de Venezuela y profesor adjunto de Derecho en la Universidad de Leyes de Columbia. 
CONTENIDO: I. LA LEGISLACIÓN PERUANA EN EL PROCESO DE CODIFICACIÓN DEL DERECHO ADMINISTRATIVO EN AMÉRICA LATINA. II. LA FINALIDAD DE LAS LEYES DE PROCEDIMIENTO ADMINISTRATIVO. III. LA ENUMERACIÓN DE LOS PRINCIPIOS DEL PROCEDIMIENTO ADMINISTRATIVO EN LAS LEYES LATINOAMERICANAS, EN PARTICULAR, EN LA LEY DEL PERÚ. - III.1. EL PRINCIPIO DEL DEBIDO PROCEDIMIENTO ADMINISTRATIVO. - III.2. EL PRINCIPIO DEL IMPULSO DE OFICIO. III.3. EL PRINCIPIO DE LA RAZONABILIDAD. - III.4. EL PRINCIPIO DE LA IMPARCIALIDAD. - III.5. EL PRINCIPIO DEL INFORMALISMO. - III.6. EL PRINCIPIO DE LA PRESUNCIÓN DE VERACIDAD. - III.7. EL PRINCIPIO DE CONDUCTA PROCEDIMENTAL. - III.8. EL PRINCIPIO DE CELERIDAD. - III.9. EL PRINCIPIO DE EFICACIA. - III.10. EL PRINCIPIO DE VERDAD MATERIAL. - III.11. EL PRINCIPIO DE LA PARTICIPACIÓN. - III.12. EL PRINCIPIO DE SIMPLICIDAD. - III.13. EL PRINCIPIO DE UNIFORMIDAD. - III.14. LOS PRINCIPIOS DE PREDICTIBILIDAD Y DE PRIVILEGIO DE CONTROLES POSTERIORES. - IV. APRECIACIÓN FINAL.

\section{LA LEGISLACIÓN PERUANA EN EL PROCESO DE CODIFICACIÓN DEL DERECHO ADMINISTRATIVO EN AMÉRICA LATINA}

El 10 de abril de 2001 se publicó en el Perú la ley 27444 del Procedimiento Administrativo General, promulgada precisamente por uno de los destacados profesores de Derecho administrativo de América Latina, el recordado amigo y entonces presidente Valentín Paniagua. Con dicha ley, redactada por un importante equipo de profesores peruanos, con el profesor Jorge Danós a la cabeza, el Perú se incorporó definitivamente en la corriente contemporánea de la codificación formal del procedimiento administrativo, siendo el texto peruano uno realmente único en el continente, pues se recogieron en él, enriquecidos, todos los principios del procedimiento administrativo que se habían venido conformando en las décadas anteriores en nuestros países por la doctrina, la jurisprudencia y la legislación ${ }^{1}$.

Este año 2011, por tanto, no solo los administrativistas peruanos sino todos los latinoamericanos estamos celebrando el décimo aniversario de la promulgación de esta importantísima ley 27444, pero, sin olvidar, por supuesto, que también este año estamos celebrando los 44 años de lo que fue su antecedente remoto, el Reglamento de Normas Generales

1 Véanse en general mis trabajos sobre el procedimiento administrativo con una perspectiva de Derecho comparado: BREWER-CARÍAS, Allan. «Principios del procedimiento administrativo en España y América Latina». En 200 años del Colegio de Abogados. Tomo I. Caracas: Colegio de Abogados del Distrito Federal, 1989, pp. 255-435; BREWER-CARÍAS, Allan. Principios del procedimiento administrativo. Madrid: Editorial Civitas, 1990; BREWER-CARíAs, Allan. Les principes de la procédure administrative non contentieuse. Études de Droit Comparé (France, Espagne, Amérique Latine). París: Editorial Económica, 1992; BreWer-CARÍAS, Allan. Principios del procedimiento administrativo en América Latina. Bogotá: Editorial Legis, 2003; y BREWER-CARíAS, Allan. «Principios del procedimiento administrativo. Hacia un estándar continental». En Christian Steiner (editor). Procedimiento y justicia administrativa en América Latina. México D.F.: Konrad Adenauer, 2009, pp. 163-199. 
de Procedimiento Administrativo dictado mediante decreto supremo 006-67-56 de 1967, y que, elevado en 1992 a rango de ley, fue precisamente sustituido por la ley 27444. Ese reglamento, no hay que olvidarlo, fue el primer cuerpo normativo en la materia en toda América Latina, y marcó la pauta para el desarrollo de las regulaciones posteriores.

En efecto, después del reglamento peruano de 1967, la primera de las leyes de procedimiento administrativo que se dictó en América Latina fue la Ley de Procedimientos Administrativos (ley 19.549) de Argentina, en 1972, reformada por la ley 21.682.

A ella la siguió el decreto ley 640 sobre procedimientos administrativos dictado en el Uruguay en 1973 y sustituido posteriormente por el decreto 500 de 1991 sobre normas generales de actuación administrativa y regulación del procedimiento en la Administración Central.

Un lustro más tarde, en 1978, se sancionó la Ley General de la Administración Pública de Costa Rica, la cual no solo reguló el procedimiento administrativo, sino materialmente todos los aspectos esenciales del Derecho administrativo, por lo que siempre la he considerado como una especie de «manual» redactado en forma de artículos de esta rama del Derecho $^{2}$. En ellos se encuentra explicado el Derecho administrativo como si se tratase del desarrollo de un programa de un curso sobre esta disciplina, expuesto en un muy hermoso y rico texto, en cuya redacción contribuyó mi recordado amigo el profesor de Derecho administrativo Eduardo Ortíz Ortíz.

Posteriormente, siguió la Ley Orgánica de Procedimientos Administrativos de Venezuela de $1981^{3}$, la cual, en la materia, fue luego complementada, con la Ley sobre Simplificación de Trámites Administrativos (decreto ley 368 del 5 de octubre de 1999, reformada en 2008) y con la Ley Orgánica de la Administración Pública de 2001, también reformada en 2008.

2 Véase: BREWER-CARíAs, Allan. "Comentarios sobre los principios generales de la Ley General de la Administración Pública de Costa Rica». Revista del Seminario Internacional de Derecho Administrativo. Colegio de Abogados de Costa Rica, 1981, pp. 31-57, San José.

3 Sobre la ley venezolana, véase BREWER-CARíAS, Allan. "Comentarios a la Ley Orgánica de Procedimientos Administrativos». Revista de Derecho Público. Editorial Jurídica Venezolana, número 7, julio-septiembre 1981, pp. 115-117, Caracas; BREWER-CARíAS, Allan. «Comentarios sobre el alcance y ámbito de la Ley Orgánica de Procedimientos Administrativos en Venezuela». Revista Internacional de Ciencias Administrativas. Institut International des Sciences Administratives, Número 3, 1983, pp. 247-258, Bruselas; BREWER-CARíAS, Allan. «Comentarios sobre el alcance y ámbito de la Ley Orgánica de Procedimientos Administrativos en Venezuela". Revista de Control Fiscal. Contraloría General de la República, número 104, 1982, pp. 113-133, Caracas; BrEWER-CARÍAS, Allan. «Introducción al régimen de la Ley Orgánica de Procedimientos Administrativos». En Allan R. Brewer-Carías (coordinador y editor). Ley Orgánica de Procedimientos Administrativos. Colección Textos Legislativos, número 1. Caracas: Editorial Jurídica Venezolana, 1981, pp. 7-51; y BREWERCARÍAs, Allan. El derecho administrativo y la Ley Orgánica de Procedimientos Administrativos. Principios del procedimiento administrativo. Sexta edición ampliada. Caracas: Editorial Jurídica Venezolana, 2002. 
Unos años más tarde, en 1984, se produjo la primera reforma general del Código Contencioso Administrativo de Colombia mediante la incorporación de un nuevo libro sobre procedimientos administrativos, cuyo contenido también se complementó con las disposiciones del decreto 266 de 2000 sobre las normas para la simplificación administrativa. El Código, luego de la reforma constitucional de 1991, fue reformado este 2011 mediante la ley 1437 contentiva del nuevo Código de Procedimiento Administrativo y de lo Contencioso Administrativo, y que se sigue configurando como pieza legislativa única en el Derecho administrativo comparado, ya que integra en un solo cuerpo normativo el régimen del procedimiento administrativo y del contencioso administrativo.

En 1987, por otra parte, se dictó la Ley de Procedimiento Administrativo de Honduras, y luego de un período de casi diez años, en 1994 se dictó en México la Ley Federal de Procedimiento Administrativo. En ese mismo año, se dictó en Ecuador el Estatuto del Régimen Jurídico Administrativo de la Función Ejecutiva (decreto ejecutivo 1634 de 1994), que solo regula aspectos del procedimiento administrativo.

Años después, en 1999, se sancionó la ley 9.784 de Brasil, la cual regula el proceso administrativo en el ámbito de la administración pública federal. Y en 2000, en Panamá, se dictó la ley 38 contentiva del Estatuto Orgánico de la Procuraduría de la Administración, que regula el procedimiento administrativo general.

$\mathrm{Al}$ año siguiente, en 2001, como indicamos al inicio, se sancionó la muy importante ley 27444 del procedimiento administrativo general de Perú, y luego, en 2002, se dictó la ley 2341 de procedimiento administrativo de Bolivia. Finalmente, en 2003, se sancionó en Chile, la ley 19.880 de procedimientos administrativos.

Todos estos textos, por otra parte, y en una forma u otra, tienen un rasgo común. Este es la influencia de la legislación española a través de las ya derogadas Ley de Régimen Jurídico de la Administración del Estado de 1957 y Ley de Procedimientos Administrativos de 1958, las cuales fueron sustituidas por la Ley de Régimen Jurídico de las Administraciones Públicas y del Procedimiento Administrativo Común (30/1992), modificada por la ley 4/1999 del 13 de enero de 1999, la cual, por su parte, influyó en la redacción de la ley peruana de 2001, por poner un ejemplo. Por ello, el Derecho administrativo latinoamericano, de haber estado influido en sus inicios solo por los principios del Derecho administrativo francés - a partir de la sanción de todas estas leyes — ha pasado a estar también influido significativamente por el Derecho administrativo español y su doctrina contemporánea.

En todo caso, el resultado de todo este proceso de positivización del Derecho administrativo ha sido que hoy podemos considerar como el 
signo más importante de la evolución del Derecho administrativo en América Latina, precisamente, el del proceso de su codificación que se ha materializado particularmente en la sanción de estas leyes reguladoras del procedimiento administrativo en general. En todos los países, además, en una forma u otra, las leyes de procedimiento administrativo dictadas han dividido la historia del Derecho administrativo en dos grandes etapas en su evolución, referidas, por supuesto, una a la etapa antes de la sanción de dichas leyes, y otra a la etapa posterior - lo que sin duda también puede decirse que ocurrió en el Perú-.

\section{LA FINALIDAD DE LAS LEYES DE PROCEDIMIENTO ADMINISTRATIVO}

Con estas leyes, en efecto, se comenzó a dar un nuevo enfoque al objeto de nuestra disciplina, es decir, a la administración pública y a su actividad, con lo que se empezó a regularla con mayor amplitud y precisión, tanto en sus aspectos sustantivos como en los referidos a su relación con los administrados. Estas leyes se apartaron entonces de las precedentes, que se referían básicamente a la organización interna de la administración - como todavía ocurre con muchos países donde aún no se han dictado-, para pasar a regular el conjunto de situaciones jurídicas en las cuales se encuentran sus relaciones recíprocas tanto la administración pública como los administrados, y donde norman el conjunto de poderes, prerrogativas y obligaciones de aquella, por una parte, y por la otra, los derechos y las obligaciones de los administrados en sus relaciones con ella.

En ello, por ejemplo, la ley peruana es precisa al indicar como su finalidad establecer el régimen en ella previsto. Es así que, busca, primero, la «protección del interés general»; segundo, que ello se haga «garantizando los derechos e intereses de los administrados», y tercero, que ambos fines se logren «con sujeción al ordenamiento constitucional y jurídico en general» (título preliminar, artículo 3). En esta forma, del contenido general de esta ley — como sucede igualmente, por ejemplo, del contenido general del Código de Procedimiento Administrativo y de lo Contencioso Administrativo de Colombia de 2011-, la enumeración de los principios del procedimiento administrativo $-\mathrm{e}$, incluso, el desarrollo legal de su significado- puede considerarse como un rasgo común de las leyes de procedimiento administrativo en América Latina, con lo que se pone en evidencia la motivación general de estos cuerpos normativos, que no es otra que el establecimiento de un régimen legal para, por una parte, guiar la acción de la administración para la producción de sus actos administrativos, y por la otra, garantizar los derechos de los administrados frente a la administración.

LA REGULACIÓN DEL

PROCEDIMIENTO

ADMINISTRATIVO

EN AMÉRICA

LATINA

(LEY 27444)

ADMINISTRATIVE PROCEDURE

REGULATION IN

LATIN AMERICA

(LAW 27444) 
Dichas leyes son, así, el resultado del mencionado proceso de lucha permanente que ha caracterizado el desarrollo de nuestra disciplina, dirigido hacia la búsqueda del necesario balance entre los privilegios de la administración pública como gestora del interés general y de los derechos de los administrados. De allí precisamente que las leyes regulen el desarrollo de la actividad de la administración para obtener la adecuada satisfacción de los intereses públicos, y, además, que busquen que los derechos de los administrados estén debidamente garantizados.

Eso es lo que se evidencia también, por ejemplo, de los considerandos de la ley de Honduras de 1987, al señalar que, en el Estado moderno, «la satisfacción de los intereses públicos exige el respeto de las formas creadas como garantía de los derechos de los particulares frente a la actividad administrativa».

Asimismo, en los considerandos del decreto ley uruguayo 500 de 1991, se precisó la motivación de todo su conjunto normativo, al establecer que tiene por objeto regular la actuación de la administración, cuando se dice que esto ocurre «a fin de servir con objetividad los intereses generales con sometimiento pleno al Derecho y para mejor tutelar los derechos e intereses legítimos de los administrados».

Eso se señala también, expresamente, por ejemplo, en el artículo 1 de la ley 9.784 de Brasil, así como en el artículo 3 del título preliminar de la ley 27444 del Perú, y es lo que se expresa con toda claridad y más ampliamente, además de incorporar el principio de legalidad, en el artículo 1 del código de Colombia al definir su finalidad.

El procedimiento administrativo, por ello, nunca puede considerarse como un fin en sí mismo, sino como un instrumento o cauce para alcanzar el fin perseguido por la administración. De allí el llamado principio de la instrumentalidad de las leyes de procedimiento, el cual permite desdoblar la finalidad del procedimiento administrativo en tres: primero, la consecución del interés general; segundo, la satisfacción del interés del administrado; y tercero, el logro del interés de la propia administración sometida a la legalidad.

En cuanto a la primera de estas finalidades, siendo el procedimiento un asunto de la administración, en él se busca «establecer el régimen jurídico aplicable para que la actuación de la Administración sirva a la protección del interés general», como hemos indicado que expresa el artículo 3 del título preliminar de la ley del Perú, o, en otras palabras, con el objeto de asegurar que el desempeño de la función pública esté destinado exclusivamente a servir los intereses de la colectividad, según el artículo 4a de la ley de Bolivia. 
Por ello, la ley de Honduras establece que los principios del procedimiento administrativo buscan «garantizar la buena marcha de la administración» (considerandos); y la Ley General de Costa Rica precisa que «el procedimiento administrativo sirve para asegurar el mejor cumplimiento posible de los fines de la Administración» (artículo 214.1), y agrega que «la norma administrativa debe ser interpretada en la forma que mejor garantice la realización del fin público a que se dirige», según su artículo 10.

Pero en segundo lugar, además del logro de los fines propios del interés general que orientan la acción administrativa, el procedimiento administrativo tiene por finalidad la protección de los derechos e intereses de los administrados. Esto, como se ha mencionado, está expresado en la Ley General de Costa Rica, donde se indica que el procedimiento administrativo debe desarrollarse «con respeto para los derechos subjetivos e intereses legítimos del administrado» (artículos 10.1 y 214.1), y también en la de Honduras, la cual establece que el procedimiento se regula «como garantía de los derechos de los particulares frente a la actividad administrativa» (considerandos). En igual sentido se expresa, como también hemos indicado, el artículo 3, título preliminar de la ley del Perú, y se expresaba, asimismo, el código colombiano de 1984, en el cual se exigía de los funcionarios que en su actuación también debía tener en cuenta «la efectividad de los derechos e intereses de los administrados» (artículo 2).

La consecuencia del mencionado principio de la instrumentalidad es, entonces, la proscripción de la utilización del procedimiento establecido en las leyes para la consecución de fines distintos a los previstos en ellas, con lo que se constituye lo contrario a un vicio de ilegalidad de la actuación de la administración por desviación de poder en el resultado. Es decir, la llamada desviación del procedimiento.

Y, en tercer lugar, la otra finalidad del procedimiento administrativo que engloba todos los principios antes mencionados es que la relación jurídica que siempre se establece entre la administración y los administrados con motivo de la actividad administrativa debe desarrollarse con sujeción al principio de legalidad. Y, en este sentido, sin duda, ha sido el proceso de positivización de principios y elementos sustantivos y adjetivos de la actividad administrativa contenida en estas leyes de procedimiento administrativo el que ha tenido una consecuencia fundamental en el desarrollo de nuestra disciplina, mediante el reforzamiento del mismo principio de la legalidad, a fin de asegurar no solo el sometimiento de la administración pública al Derecho, sino de garantizar la situación jurídica de los particulares frente a la misma. Por ello, precisamente, la ley sobre procedimiento administrativo general del Perú, en su artículo 4.1.1 del título preliminar, dispone que «las autoridades administrativas

LA REGULACIÓN

DEL

PROCEDIMIENTO

ADMINISTRATIVO

EN AMÉRICA

LATINA

(LEY 27444)

ADMINISTRATIVE

PROCEDURE

REGULATION IN

LATIN AMERICA

(LAW 27444) 
deben actuar con respeto a la Constitución, la ley y al derecho, dentro de las facultades que le estén atribuidas y de acuerdo con los fines para los que les fueron conferidas».

Ello ha implicado, en relación con el principio de legalidad —y precisamente como consecuencia de las propias leyes de procedimiento administrativo- , que dicho principio haya dejado de ser solo un principio general del derecho y se haya convertido en un postulado del Derecho positivo, expresado formalmente, y cada vez con más frecuencia y precisión, en los textos, como es el caso del artículo 1 del código de Colombia, cuando identifica expresamente como «finalidad» de las normas de su libro primero el hecho de asegurar «la sujeción de las autoridades a la Constitución y demás preceptos del ordenamiento jurídico».

Así también sucede, por ejemplo, en la ley de Bolivia, que hace referencia al «principio de legalidad y a la presunción de legitimidad» (artículo $4 \mathrm{~g}$ ) y al «principio de sometimiento pleno a la ley», de manera que «la Administración Pública regirá sus actos con sometimiento pleno a la ley, asegurando a los administrados el debido proceso» (artículo 4c). Igualmente, la ley 9784 de Brasil impone como criterio a ser observado en los procedimientos administrativos «la actuación conforme a la Ley y al derecho» (artículo 2, parágrafo único), así como también la ley de Venezuela indica que «la Administración Pública se organiza y actúa de conformidad con el principio de legalidad» (artículo 4), y la ley general de Costa Rica señala que «la Administración Pública actuará sometida al ordenamiento jurídico [...]» (artículo 11.1), para luego agregar en su artículo 13 que «[...] la Administración estará sujeta, en general, a todas las normas escritas y no escritas del ordenamiento administrativo y al derecho privado supletorio del mismo, sin poder derogarlos ni desaplicarlos para casos concretos».

Este principio de legalidad o de actuación en conformidad con el Derecho implica, por tanto, que las actividades que realice la administración pública no solo deben someterse a él, sino, en el caso del procedimiento administrativo, a los propios principios de este que también forman parte del Derecho positivo, lo que implica que las actividades contrarias a dichos principios pueden ser controladas con mayor precisión por los tribunales de la jurisdicción contencioso-administrativa.

Por ello, a dichos principios en el código colombiano se los declara como imperativos, al disponer expresamente que todas las autoridades deben «interpretar y aplicar las disposiciones que regulan las actuaciones y procedimientos administrativos a la luz de los principios consagrados en la Constitución Política, en la Parte Primera de este Código y en las leyes especiales» (artículo 3$)$. 
En igual sentido, la ley federal mexicana prescribe que las disposiciones sobre procedimiento administrativo «son aplicables a la actuación de los particulares ante la Administración Pública Federal, así como a los actos a través de los cuales se desenvuelve la función administrativa» (artículo 12). En el caso de la ley general de Costa Rica se precisa que es en aquellos procedimientos en los cuales «el acto final puede causar perjuicio grave al administrado, sea imponiéndole obligaciones, suprimiéndole o denegándole derechos subjetivos, o por cualquier otra forma de lesión grave y directa a sus derechos o intereses legítimos», o en los cuales haya habido «contradicción o concurso de interesados frente a la Administración dentro del expediente» (artículo 308).

El Derecho administrativo en América Latina, por tanto, como resultado de este estándar continental que ya existe en materia de los principios del procedimiento administrativo y que ha quedado plasmado en forma destacada en el Código de Procedimiento Administrativo y de lo Contencioso Administrativo de Colombia, sin duda se encuentra en una situación de avanzada que hace décadas, quienes nos ocupamos del Derecho comparado, solo soñábamos.

Siendo todos los aspectos antes mencionados parte esencial de la finalidad y sentido central de la regulación de las leyes, estas cambiaron totalmente la situación tradicional de las relaciones entre la administración y los administrados —en las cuales el balance estaba siempre a favor de la primera, con amplias regulaciones sobre sus poderes, potestades y prerrogativas - y sobre las obligaciones de los administrados, y pocas sobre los derechos de estos últimos. Ese balance fue el que se cambió sustancialmente con las leyes de procedimiento administrativo, a fin de encontrar una situación de equilibrio entre los poderes de la administración y los derechos de los administrados — los cuales se buscó garantizar en las leyes- con lo que se pasó a reforzar el principio de la legalidad.

En esta orientación, al cambiar totalmente el desbalance de los dos extremos de la relación de Derecho administrativo y establecerse el necesario equilibrio entre ellos, las leyes de procedimiento administrativo han contribuido a generar en todos los países un cambio de actitud y de forma y método del actuar de la administración pública, con lo que se procura lograr que la administración dejara de ser prepotente, ya que solo concedía dádivas o favores al administrado, quien, por su parte, no tenía derechos, ni cómo reclamarlos, y era aplastado - y a veces vejado- por la administración. Con las nuevas leyes se sentaron las bases para que ello cambiara, de manera que el administrado que iba a enfrentar la administración ya no fuera un sujeto indefenso, sino uno bien armado con muchos derechos frente a ella y con muchos mecanismos jurídicos para garantizarlos y para controlar cualquier actitud que significara su desmejora. 
Otro rasgo común del conjunto normativo sobre procedimientos administrativos en América Latina es que estas leyes han abarcado todo el proceso de producción de las decisiones administrativas, lo que conduce a una muy importante regulación en relación con los actos administrativos, al punto de que podemos considerar que casi todas estas leyes son, básicamente, leyes relativas al régimen jurídico del acto administrativo. Así sucede, por supuesto, en el Perú donde el título primero de la ley se dedica a normar el régimen jurídico de los actos administrativos, de manera que, en el artículo 29, al definir el procedimiento administrativo, se lo entiende como «el conjunto de actos y diligencias tramitados en las entidades, conducentes a la emisión de un acto administrativo que produzca efectos jurídicos individuales o individualizables sobre intereses, obligaciones o derechos de los administrados».

Por ello es que, por otra parte, en el desarrollo del Derecho administrativo hayan sido estas leyes las piezas esenciales para el afianzamiento del principio de la legalidad ${ }^{4}$, al punto de que se pueda encontrar en ellas, como sucede con la ley peruana, la definición de dicho principio (título preliminar, artículo 4.1.1).

Por otra parte, todas estas leyes de procedimiento administrativo se han configurado con una universalidad adecuada, de manera que han llegado a constituir cuerpos normativos que incluso se aplican obligatoriamente a todas las autoridades administrativas, y no solo a la administración pública del Poder Ejecutivo, e, incluso, a los demás órganos del Estado cuando actúan en ejercicio de la función administrativa. Ello es lo que explica que la ley peruana, al decir que se aplica a «todas las entidades de la Administración Pública», entienda a sus fines no solo al Poder Ejecutivo -incluyendo ministerios y organismos públicos descentralizados-, a los gobiernos regionales y locales, y a las demás entidades y organismos, proyectos y programas del Estado cuyas actividades se realizan en virtud de potestades administrativas, sino también al Poder Legislativo, al Poder Judicial y a los organismos a los que la Constitución Política del Perú y las leyes confieren autonomía, y, asimismo, a las personas jurídicas bajo el régimen privado que prestan servicios públicos o ejercen función administrativa, en virtud de concesión, delegación o autorización del Estado (título preliminar, artículo 1).

Esta es una previsión de gran importancia y que recoge lo que es un signo común en el Derecho administrativo latinoamericano, donde la administración y la actividad administrativa en sentido lato están

4 Véase: BREWER-CARÍAS, Allan. «El principio de la legalidad en la Ley Orgánica de Procedimientos Administrativos". Revista del Consejo de la Judicatura. Número 22, julio-septiembre 1981, pp. 5-14, Caracas; BREWER-CARíAs, Allan. «El tratamiento del principio de la legalidad en las leyes de procedimiento en América Latina». Revista AIDA. Número 8, 2010, México D.F. 
desligadas del Poder Ejecutivo y son las de los otros poderes del Estado las que constituyen administraciones públicas.

\section{LAENUMERACIÓNDELOSPRINCIPIOSDELPROCEDIMIENTO ADMINISTRATIVO EN LAS LEYES LATINOAMERICANAS, EN PARTICULAR, EN LA LEY DEL PERÚ}

Otra característica general o rasgo común de estas leyes de procedimiento administrativo en América Latina ha sido su enumeración en el propio texto. Por tanto, ahora ya no tienen que ser deducidos por el juez mediante interpretación, y le permiten particularmente al juez contencioso administrativo tener más precisas herramientas de control sobre la actuación administrativa.

La pauta en esta materia la marcó la primera de las leyes de procedimiento administrativo sancionadas en el continente, que fue la ley argentina, en la cual se enumeraron los principios que debían guiarlo, y se incluyen la «celeridad, economía, sencillez y eficacia en los trámites» (artículo 1b), principios que fueron recogidos posteriormente en todas las leyes posteriores en un proceso de aproximaciones sucesivas, donde se fueron incorporando otros principios y se amplió la enumeración.

Así sucedió en la ley de Honduras en la década de los ochenta, donde se repitieron los mismos principios (artículo 19), igual que sucedió en la ley venezolana, en donde se agregó a la lista, sin embargo, el principio de imparcialidad (artículo 30). Estos últimos principios con arreglo, a los cuales se debían desarrollar las actuaciones administrativas, se repitieron en el código colombiano de 1984, agregándose los de «publicidad y contradicción» (artículo 3).

La enumeración del código de Colombia se siguió ya en la década de los noventa en la ley de México, donde se agregó a la misma enumeración inicial el principio de la buena fe (artículo 13), que luego fue incorporado en varias legislaciones, entre ellas en la reforma del código de Colombia de 2011. Igualmente en la década de los noventa, en la ley ecuatoriana, a los principios ya arraigados en las leyes anteriores se agregaron los de informalidad y uniformidad, además de la indicación de que la función administrativa debía realizarse «sin menoscabo del debido proceso legal, con objetividad y con apego al principio de estricta legalidad» (artículo 34). Igualmente en Ecuador, en la Ley de Modernización del Estado, al referirse a los procesos de modernización, se agregaron a los principios tradicionales los de transparencia, coparticipación en la gestión pública y solidaridad social.

Igualmente, en la ley 38 de Panamá de 2000, entre los principios con apego a los cuales debe actuar la administración pública, además de los

LA REGULACIÓN

DEL

PROCEDIMIENTO

ADMINISTRATIVO

EN AMÉRICA

LATINA

(LEY 27444)

ADMINISTRATIVE

PROCEDURE

REGULATION IN

LATIN AMERICA

(LAW 27444) 
clásicos se agregan los principios de «calidad, transparencia y moralidad en la prestación de los servicios públicos» (artículo 3.2). Algo similar ocurrió a finales de la década de los noventa en la ley de Brasil: a los ya asentados principios previstos en varias leyes se agregaron los «principios da finalidade, motivaçao, razoabilidade, proporcionalidade, segurança juridica, interesse público» (artículo 2). E igualmente en la última de las leyes, que fue la ley 19.880 de procedimientos administrativos de Chile de 2003, a los principios ya adoptados de otras legislaciones se agregaron los de «escrituración, conclusivo, abstención, no formalización, inexcusabilidad, impugnabilidad [...]» (artículo 4).

Pero en ese proceso de aproximaciones sucesivas y de progresividad en la definición de principios del procedimiento, debe destacarse el aporte que significó en materia legislativa en la década de los noventa la amplia y comprensiva enumeración que se incluyó en el decreto ley de Uruguay, donde, en el artículo 2, además de indicarse que la administración pública debe servir con objetividad los intereses generales con sometimiento pleno al derecho (legalidad objetiva), y de enumerarse los clásicos principios ya indicados conforme a los cuales debe actuar - «economía, celeridad, eficacia, imparcialidad, informalismo en favor del administrado, contradicción, imparcialidad, buena fe, motivación de la decisión y gratuidad»-, se agregaron los principios de «impulsión de oficio; verdad material; flexibilidad, materialidad y ausencia de ritualismos; delegación material; debido procedimiento; lealtad y presunción de verdad salvo prueba en contrario».

Siguiendo esta orientación de enumeración exhaustiva en algunos casos los principios fueron establecidos con rango constitucional, como es el caso de la Constitución de Venezuela de 1999, en cuyo artículo 141 se precisó que «la Administración Pública está al servicio de los ciudadanos y se fundamenta en los principios de honestidad, participación, celeridad, eficacia, eficiencia, transparencia, rendición de cuentas y responsabilidad en el ejercicio de la función pública, con sometimiento pleno a la ley y al derecho».

Adicionalmente, en el caso de Venezuela, la Ley de Simplificación de Trámites Administrativos de 1999, reformada en 2008, agregó los siguientes principios a los ya enumerados en la Constitución o en la ley de procedimientos administrativos — simplicidad, transparencia, celeridad, eficacia, eficiencia, rendición de cuentas, responsabilidad en el ejercicio de la función pública一: «simplicidad, solidaridad, presunción de buena fe del interesado, desconcentración en la toma de decisiones por parte de los órganos de dirección y su actuación debe estar dirigida al servicio de las personas». Esta formalización de principios se repitió en el artículo 10 de la Ley Orgánica de la Administración Pública de 2001, reformada en 2008, al precisar, además de los ya expresados formalmente 
— «economía, celeridad, simplicidad, rendición de cuentas, eficacia, eficiencia, objetividad, imparcialidad, uniformidad, modernidad, transparencia, buena fe, y responsabilidad en el ejercicio de la misma»—, «los principios de, proporcionalidad, oportunidad, objetividad, participación, honestidad, accesibilidad, modernidad, buena fe, paralelismo de la forma con sometimiento pleno a la ley y al derecho, y con supresión de las formalidades no esenciales».

Lamentablemente, sin embargo, a pesar de estas declaraciones, la situación venezolana no es un ejemplo de efectividad en materia de aplicación de estos principios, a pesar incluso del rango constitucional, siendo claro y evidente que ellos, por más excelsos que sean —y por más florido que sea el lenguaje de su enunciado- no son más que letra muerta cuando se está en presencia de un régimen autoritario como el que actualmente padece mi país, donde no hay jueces contencioso administrativos con autonomía e independencia capaces, o dispuestos de asegurar su aplicación general.

Pero dejando aparte esta lamentable situación, lo cierto es que el proceso de positivización de los principios del procedimiento administrativo se ha ido ampliando en América Latina, siendo un ejemplo importante de avance la ley del Perú de 2001, donde positivizaron, resumieron y actualizaron todos los principios que hemos indicado, al precisarse en el artículo 4 del título preliminar que el procedimiento administrativo, sin perjuicio de la vigencia de otros principios generales del Derecho administrativo, se sustenta fundamentalmente en los siguientes principios enumerados, además — según se indica-, a título enunciativo y no taxativo: los «principios de legalidad; del debido procedimiento; del impulso de oficio; de razonabilidad; de imparcialidad; de informalismo; de presunción de veracidad; de conducta procedimental; de celeridad; de eficacia; de verdad material; de participación; de simplicidad; de uniformidad; de predictibilidad; y de privilegio de controles posteriores».

La culminación de este proceso de formalización y positivización de los principios, en todo caso, puede ubicarse en la ley de Bolivia de 2002, en la cual, en su artículo 4, no solo se enumera, sino que incluso, como en la ley del Perú o como lo hace el código colombiano - pero más exhaustivamente-, se definen los siguientes principios a los que debe sujetarse la administración pública: autotutela, sometimiento pleno a la ley, verdad material, buena fe, imparcialidad, legalidad y presunción de legitimidad, jerarquía normativa, control judicial, eficacia, economía, simplicidad y celeridad, informalismo, publicidad, impulso de oficio, gratuidad, y proporcionalidad.

Lo importante de la enunciación de los principios que deben guiar la actuación de la administración, en todo caso, como se señala en el artículo 2 de la ley de Brasil, el artículo 3 del código colombiano

LA REGULACIÓN

DEL

PROCEDIMIENTO

ADMINISTRATIVO

EN AMÉRICA

LATINA

(LEY 27444)

ADMINISTRATIVE

PROCEDURE

REGULATION IN

LATIN AMERICA

(LAW 27444) 
y el artículo 4.2 de la ley del Perú, es que deben servir como criterio interpretativo para resolver las cuestiones que puedan suscitarse en la aplicación de las normas de procedimiento, y, además, como lo dice la ley de Honduras (artículos 19 y 114) y la ley del Perú (artículo 4.2 del título preliminar), «como parámetros para la generación de otras disposiciones administrativas de carácter general, y para suplir los vacíos en el ordenamiento administrativo».

Por ello, una enumeración extensa de principios del procedimiento administrativo, como la contenida en las leyes de Brasil, Uruguay, Bolivia, Perú y en el código de Colombia, sin duda, tiene la ventaja de permitir al juez contencioso administrativo ejercer un control más efectivo y con mayor amplitud en relación con la actividad administrativa. Para ello, además, es claro que más importante que la sola enumeración de los principios, como antes dije, es la definición en los textos legales de su contenido, como ocurre con el mencionado artículo 4 de la ley de Bolivia, con el artículo 3 del código colombiano (artículo 3), y con el artículo 4 del título preliminar de la ley del Perú.

Todos estos principios, por supuesto, no nacieron con estas leyes. Mucho antes de que las mismas se comenzaran a sancionar, se habían venido construyendo fundamentalmente por la jurisprudencia contencioso administrativa, con la ayuda de la doctrina, habiéndose logrado su positivización y adquiriendo rango legal precisamente con las leyes, lo que ha permitido al juez contencioso administrativo ejercer con mayor precisión el control de legalidad de la actuación administrativa, y ha catapultado, en consecuencia, tanto a la jurisprudencia como a la doctrina en materia contencioso administrativa.

Es precisamente en este marco general que quiero referirme ahora a los principios del procedimiento administrativo tal como se enumeraron en la ley 27444 del Perú sobre procedimiento administrativo general, a fin de comparar su enunciado con el que se establece en otras leyes de procedimiento administrativo de América Latina.

\section{III.1. El principio del debido procedimiento administrativo El primero de los principios enunciados en el Código peruano, aparte del principio de legalidad antes indicado, es el principio del debido proceso, que aplicado al procedimiento administrativo se ha definido en el artículo 4.1.2 del título preliminar como «principio del debido procedimiento» y de la siguiente manera:}

IV. 1.2. Principio del debido procedimiento. Los administrados gozan de todos los derechos y garantías inherentes al debido procedimiento administrativo, que comprende el derecho a exponer sus argumentos, a ofrecer y producir pruebas y a obtener una decisión motivada y fundada 
en derecho. La institución del debido procedimiento administrativo se rige por los principios del Derecho Administrativo. La regulación propia del Derecho Procesal Civil es aplicable solo en cuanto sea compatible con el régimen administrativo.

Esta precisión era necesaria en la ley, pues en la Constitución del Perú, el debido proceso se establecía como un principio de la «función jurisdiccional» (artículo 139.3), distinto a como sucede en otros países, como en Colombia, donde la garantía constitucional al debido proceso consagrada en la Constitución de 1991, además de a los procesos judiciales se aplica a los procedimientos administrativos. Así lo prevé expresamente el artículo 49 de la Constitución de Colombia al indicar que «el debido proceso se aplicará a toda clase de actuaciones judiciales y administrativas», enunciado que se copió en el artículo 49 de la Constitución venezolana de 1999, en el cual se precisó, además, su contenido esencial, al abarcar el derecho a la defensa y asistencia jurídica, la presunción de inocencia, el derecho a ser oído, el derecho al juez natural, el derecho a la no autoincriminación, el principio nullum crimen nulla poena sine lege - de manera que las sanciones administrativas estén en leyes preexistentes-, el principio non bis in idem, y el principio de la responsabilidad del Estado por errores procesales. Todos estos principios, por tanto, rigen como garantía constitucional en los procedimientos administrativos. Fue en esta orientación que en la reforma del código colombiano de 2010 para adaptarlo a la Constitución también se enunció el principio del debido proceso en relación con el procedimiento administrativo, y se indicó en el artículo 3.1 que, en virtud del mismo «las actuaciones administrativas se adelantarán de conformidad con las normas de procedimiento y competencia establecidas en la Constitución y la ley, con plena garantía de los derechos de representación, defensa y contradicción». Agregó además el código colombiano que «en materia administrativa sancionatoria», se debe observar «los principios de legalidad de las faltas y de las sanciones (nulla poena sine lege), de presunción de inocencia, de no reformatio in pejus y non bis in idem», y se destacó de esta enumeración la importante formalización legal que significa el principio de la no reformateo in pejus, cuyo fundamento ha sido en todos los países, básicamente, de carácter jurisprudencial. Sin duda, es una previsión única en el derecho comparado.

\section{III.2. El principio del impulso de oficio}

En la ley peruana también se estableció el principio del impulso de oficio, al establecer el artículo 4.1.3 que «las autoridades deben dirigir e impulsar de oficio el procedimiento y ordenar la realización o práctica de los actos que resulten convenientes para el esclarecimiento y resolución de las cuestiones necesarias». 
Se trata de un principio derivado del principio de la oficialidad, también denominado «principio inquisitivo», conforme al cual, como lo establece en la ley argentina, corresponde a la administración, la «impulsión e instrucción de oficio», sin perjuicio de la participación de los interesados en las actuaciones (artículo 1a).

Este principio también está establecido como principio del procedimiento administrativo en la ley de Bolivia (artículo 4n), y la misma expresión se encuentra en las leyes de Brasil (artículo 29) y de Costa Rica (artículo 222) y, en sentido similar, se desarrolla en la ley del Perú (artículo 159). De ello deriva el principio de que la administración debe «impulsar de oficio en todos sus trámites» (artículo 64 de la ley de Honduras) del procedimiento administrativo, con lo cual la conducción del procedimiento, la prueba y las medidas que puedan adoptarse a lo largo del mismo deben ser iniciativa de la administración y no requieren el impulso procesal de los interesados, sin perjuicio de que estos puedan participar en el procedimiento. En consecuencia, la administración es la responsable de al menos esos tres elementos en el procedimiento: la conducción del procedimiento, la sustanciación del mismo, las pruebas y las medidas preventivas, sin perjuicio de que en cada una de esas fases puedan actuar los particulares.

Por ello, la ley de Venezuela establece que «la Administración, de oficio o a instancia del interesado, cumplirá todas las actuaciones necesarias para el mejor conocimiento del asunto que deba decidir, siendo de su responsabilidad impulsar el procedimiento en todos sus trámites».

\section{III.3. El principio de la razonabilidad}

Otro importante principio expresado en la ley peruana es el principio de la razonabilidad, al indicarse en el artículo 4.1.4 que «las decisiones de la autoridad administrativa, cuando creen obligaciones, califiquen infracciones, impongan sanciones, o establezcan restricciones a los administrados, deben adaptarse dentro de los límites de la facultad atribuida y manteniendo la debida proporción entre los medios a emplear y los fines públicos que deba tutelar, a fin de que respondan a lo estrictamente necesario para la satisfacción de su cometido».

La enunciación de este principio, en esta forma y con esta denominación, es única en las leyes de procedimiento administrativo de América Latina, y se encuentra en ellas el mismo principio y sentido, fundamentalmente al definirse los límites al poder discrecional de la administración. Así sucede, por ejemplo, en varias normas de la Ley General de la Administración Pública de Costa Rica. El artículo 15.1 de la ley general, en efecto, comienza por prescribir que el ejercicio del poder discrecional está «sometido en todo caso a los límites que le impone el 
ordenamiento expresa o implícitamente, para lograr que su ejercicio sea eficiente y razonable», atribuyéndole al juez potestad para controlar la legalidad no solo sobre los aspectos reglados del acto discrecional, sino «sobre la observancia de sus límites» (artículo 15.2). Ello lo refuerza la propia ley general al prescribir en su artículo 216 que «la Administración deberá adoptar sus resoluciones dentro del procedimiento con estricto apego al ordenamiento y, en el caso, de las actuaciones discrecionales, a los límites de racionalidad y razonabilidad implícitos en aquél».

El artículo 16.1 es reiterativo en cuanto a este principio, al establecer que «en ningún caso podrán dictarse actos contrarios a reglas unívocas de la ciencia o de la técnica, o a principios elementales de justicia, lógica o conveniencia» (artículo 16.2). Otro límite al ejercicio del poder discrecional en la ley de Costa Rica se establece en relación a «los derechos del particular» (artículo 17) frente a la discrecionalidad.

La ley general, además, consagra expresamente la consecuencia del traspaso de los límites mencionados por la autoridad administrativa al prescribir, en el artículo 158, como una causa de invalidez de los actos administrativos, la infracción a las reglas técnicas y científicas de sentido unívoco y aplicación exacta, en las circunstancias del caso, y agrega en el artículo 160, que «el acto discrecional será inválido, además, cuando viole reglas elementales de lógica, de justicia o de conveniencia, según lo indiquen las circunstancias del caso».

Por último, es de destacar el artículo 133 de la misma ley general, el cual regula los motivos del acto administrativo, y establece que cuando este no esté regulado, «deberá ser proporcionado al contenido y cuando esté regulado en forma imperiosa deberá ser razonablemente conforme con los conceptos indeterminados empleados por el ordenamiento». El principio de la proporcionalidad también es repetido por la ley general en el artículo 132.1, al prescribir que debe ser «proporcionado al fin legal» del acto.

Es difícil, ciertamente, encontrar otro ejemplo de legislación positiva en el mundo con normas tan precisas y ricas en su contenido, para que los jueces puedan controlar el ejercicio del poder discrecional con precisas referencias a los principios de razonabilidad, racionalidad, justicia, lógica, proporcionalidad y conveniencia.

La ley venezolana de procedimientos administrativos de 1982 recogió también el principio de los límites al ejercicio del poder discrecional en la norma que hemos comentado del artículo 12, cuando prescribe que «aún cuando una disposición legal o reglamentaria deje alguna medida o providencia a juicio de la autoridad competente, dicha medida o providencia deberá mantener la debida proporcionalidad y adecuación con 
el supuesto de hecho y con los fines de la norma, y cumplir los trámites, requisitos y formalidades necesarios para su validez y eficacia».

Se consagró, así, expresamente, como antes hemos analizado, no solo la existencia de elementos reglados del acto discrecional que siempre deben respetarse - adecuación con los presupuestos de hecho, adecuación con la finalidad, competencia legal o reglamentaria, respeto de las formas y procedimiento-, sino que se erigió como límite fundamental al ejercicio del poder discrecional, la obligación del funcionario de «mantener la debida proporcionalidad». Así se estableció también en el artículo 36 del Código Contencioso Administrativo de Colombia: «en la medida en que el contenido de una decisión, de carácter general o particular, sea discrecional, debe ser adecuada a los fines de la norma que la autoriza, y proporcional a los hechos que le sirven de causa».

\section{III.4. El principio de la imparcialidad}

El principio de la imparcialidad también se definió en la ley del Perú, al indicar el artículo 4.1.5 que «las autoridades administrativas actúan sin ninguna clase de discriminación entre los administrados, otorgándoles tratamiento y tutela igualitarios frente al procedimiento, resolviendo conforme al ordenamiento jurídico y con atención al interés general».

Conforme a este principios, la administración, en el curso del procedimiento administrativo y al decidirlo, no debe tomar partido, ni inclinar la balanza o beneficiar ilegítimamente a una parte en perjuicio de otra, sino que debe tomar su decisión objetivamente, únicamente conforme al ordenamiento jurídico y con la finalidad de interés general que la motiva, tratando a todos los ciudadanos en forma igual, salvo las distinciones que deriven de los derechos de protección que puedan tener ciertos ciudadanos.

Este principio también se ha establecido en la ley de Bolivia al disponer que «las autoridades administrativas deben actuar en defensa del interés general, evitando todo género de discriminación o diferencia entre los administrados» (artículo 4f), y se encuentra regulado el artículo 30 de la ley venezolana, cuando exige a la administración tratar en igual forma a todos los particulares, sin establecer ningún tipo de discriminación respecto de ellos, ni parcializarse por ninguna posición.

También se establece en la ley 19.880 de Chile, cuando se lo vincula con el principio de la probidad, al disponer en su artículo 11 que «la Administración debe actuar con objetividad y respetar el principio de probidad consagrado en la legislación, tanto en la substanciación del procedimiento como en las decisiones que adopte.» A los efectos de poder controlar la aplicación del principio, la ley chilena agrega, en materia de actos administrativos, la exigencia de la motivación de los mismos, 
en el sentido de que «los hechos y fundamentos de derecho deberán siempre expresarse en aquellos actos que afectaren los derechos de los particulares, sea que los limiten, restrinjan, priven de ellos, perturben o amenacen su legítimo ejercicio, así como aquellos que resuelvan recursos administrativos».

\section{III.5. El principio del informalismo}

La Ley del Perú, en cuanto al principio del informalismo, dispone en su artículo 4.1.6 que «las normas de procedimiento deben ser interpretadas en forma favorable a la admisión y decisión final de las pretensiones de los administrados, de modo que sus derechos e intereses no sean afectados por la exigencia de aspectos formales que puedan ser subsanados dentro del procedimiento, siempre que dicha excusa no afecte derechos de terceros o el interés público».

Siendo que el procedimiento administrativo se configura como un conjunto de actos y actuaciones estrechamente vinculados entre sí, con el objeto de obtener un resultado concreto que, generalmente, se materializa en un acto administrativo, se considera que la prescripción de dichas formas no puede convertir al procedimiento en un bosque de formalidades que, como fin en sí mismas, entraben la acción administrativa.

Este principio, por ejemplo, también está expresamente previsto con ese nombre en la ley argentina de procedimiento administrativo, en la cual se prescribe que las normas de procedimiento que establece deben ajustarse al requisito del «informalismo», en el sentido de que debe «excusarse la inobservancia por los interesados de exigencias formales no esenciales y que pueden ser cumplidas posteriormente» (artículo 1c). En la ley de Bolivia se define el principio en el sentido de que «la inobservancia de exigencias formales no esenciales por parte del administrado, que puedan ser cumplidas posteriormente, podrán ser excusadas y ello no interrumpirá el procedimiento administrativo» (artículo 4.l).

Más precisamente, el decreto 640 de Uruguay establece que «en el procedimiento administrativo se aplicará el principio del informalismo en favor del administración siempre que se trate de la inobservancia de exigencias formales no esenciales y que puedan ser cumplidas posteriormente» (artículo 23).

Por su parte, la ley 19.880 de Chile regula el principio, al que denomina «de la no formalización», cuando dice que «el procedimiento debe desarrollarse con sencillez y eficacia, de modo que las formalidades que se exijan sean aquéllas indispensables para dejar constancia indubitada de lo actuado y evitar perjuicios a los particulares». 


\section{III.6. El principio de la presunción de veracidad}

El principio de la presunción de veracidad también se define en la ley peruana, en cuyo artículo IV.1.7 se dispone que «en la tramitación del procedimiento administrativo, se presume que los documentos y declaraciones formulados por los administrados en la forma prescrita por esta Ley, responden a la verdad de los hechos que ellos afirman. Esta presunción admite prueba en contrario».

Este principio se han configurado como una presunción a favor del ciudadano, como se indica, por ejemplo, en la Ley de Simplificación de Trámites Administrativos de Venezuela de 1999, reformada en 2008 (artículos 9 a 20), en el sentido de que la administración, en todas sus actuaciones, «debe tener como cierta la declaración del administrado» (artículo 9). El principio lo denominaba el artículo 3 del decreto 266 de 2000 de Colombia, sobre simplificación de trámites, como «presunción de veracidad», y en Uruguay se manifiesta como «presunción de licitud» vinculada a derecho del administrado a la presunción de inocencia. Así se expresa en dicha ley uruguaya en relación con los procedimientos disciplinarios de funcionarios públicos, al garantizársele el «derecho al respeto de su honra y al reconocimiento de su dignidad» y a que se presuma «su inocencia mientras no se establezca legalmente su culpabilidad por resolución firme dictada con la garantía del debido proceso (artículo 170). Este principio de la «presunción de licitud» ha sido formulado en general en la ley peruana, al definírselo en el sentido de que las entidades «deben presumir que los administrados han actuado apegados a sus deberes mientras no cuenten con evidencia en contrario» (artículo 230.9), lo que implica la presunción de que el derecho reclamado por el administrado es justo.

\section{III.7. El principio de conducta procedimental}

Otro principio que se establece en la ley peruana es el de conducta procedimental. En el artículo 4.1.8 se dice de ella que «la autoridad administrativa, los administrados, sus representantes o abogados y, en general, todos los partícipes del procedimiento, realizan sus respectivos actos procedimentales guiados por el respeto mutuo, la colaboración y la buena fe. Ninguna regulación del procedimiento administrativo puede interpretarse de modo tal que ampare alguna conducta contra la buena fe procesal».

Este principio se ha configurado en general en la legislación latinoamericana como el procedimiento de la buena fe, que también se ha introducido en la reforma del código de Colombia de 2011, y responde al enunciado general del artículo 83 de la Constitución de 1991 en el sentido de que «las actuaciones de los particulares y de las autoridades públicas deberán ceñirse a los postulados de la buena fe, la cual se 
presumirá en todas las gestiones que aquellos adelanten ante estas». En esta orientación, el artículo 3.4 del código colombiano dispone que, en virtud del principio de la buena fe, «las autoridades y los particulares deben presumir el comportamiento leal y fiel de unos y otros en el ejercicio de sus competencias, derechos y deberes».

El principio, además de en Perú y Colombia, se había enunciado en el decreto ley uruguayo y en las leyes de Venezuela, Brasil y Bolivia, en donde podía considerarse como una revolución en el régimen jurídico de la administración pública, ya que en la práctica de algunas administraciones públicas lo que ha existido de parte de los funcionarios públicos hacia los administrados ha sido, al contrario, una especie de presunción de que los últimos actúan de mala fe, por lo que, usualmente, buscan obstaculizar sus pretensiones. Y los administrados, por su parte, con frecuencia responden a esta actitud buscando engañar a la administración. El principio de la buena fe, al contrario, como lo enuncia la Constitución colombiana, tendría que convertirse en el instrumento que pueda garantizarle al administrado el poder confiar en la administración y en sus funcionarios y viceversa, de manera que debe regir tanto para el administrado como para la administración.

En particular, en la ley de Uruguay, se impone a las partes, a sus representantes y a los abogados patrocinantes, a los funcionarios públicos y, en general, todos los partícipes del procedimiento el ajustar su conducta «al respeto mutuo y a la lealtad y buena fe». En el artículo 4e de la ley de Bolivia, se establece que en la relación de los particulares con la administración pública «se presume el principio de buena fe», y se indica que «la confianza, la cooperación y la lealtad en la actuación de los servidores públicos y de los ciudadanos» deben orientar el procedimiento administrativo.

El principio se recoge igualmente en la ley de Brasil, donde entre los deberes del administrado interesado en un procedimiento está «el proceder con lealtad, urbanidad y buena fe», el de no actuar de modo temerario y el de «exponer los hechos conforme a la verdad» (artículo 4). Se destaca de esta previsión, vinculado a la buena fe, el principio de lealtad, que implica que las partes en el procedimiento no deben ocultar hechos o documentos que sean de interés mutuo, lo que a la vez está relacionado con principios tan importantes en décadas pasadas como el de publicidad, el de acceso a la información en materia administrativa y el de reducción de las áreas de confidencialidad en los documentos administrativos.

El respeto mutuo que deriva del principio de la buena fe y del principio de la lealtad, por otra parte, comienza a ser el canal para la construcción del principio de la confianza legítima que debe existir como base de la relación jurídica entre la administración y los administrados,

LA REGULACIÓN DEL

PROCEDIMIENTO ADMINISTRATIVO EN AMÉRICA

LATINA

(LEY 27444)

ADMINISTRATIVE PROCEDURE

REGULATION IN

LATIN AMERICA

(LAW 27444) 
particularmente cuando las actuaciones reiteradas de los funcionarios y de los órganos de la administración pública hacen nacer expectativas jurídicas legítimas en la cabeza de aquellos que la propia administración debe respetar —y que han de ser apreciadas por el juez—.

\section{III.8. El principio de celeridad}

En cuanto al principio de celeridad, tan común en todas las leyes de procedimiento administrativo, en el artículo 4.1.9 de la ley de Perú se dice que «quienes participan en el procedimiento deben ajustar su actuación de tal modo que se dote al trámite de la máxima dinámica posible, evitando actuaciones procesales que dificulten su desenvolvimiento o constituyan meros formalismos, a fin de alcanzar una decisión en tiempo razonable, sin que ello releve a las autoridades del respeto al debido procedimiento o vulnere el ordenamiento».

Conforme a este principio, como se indica en el código colombiano, las autoridades deben impulsar oficiosamente los procedimientos e incentivar «el uso de las tecnologías de la información y las comunicaciones, a efectos de que los procedimientos se adelanten con diligencia, dentro de los términos legales y sin dilaciones injustificadas» (artículo 3.13).

Si el procedimiento administrativo es un asunto de la administración, siendo la misma responsable de su desarrollo, el principio consecuencial establecido en garantía de los particulares es que este debe ser desarrollado con la mayor rapidez y celeridad posible.

En otras legislaciones también se enuncia el principio de la celeridad, como es el caso por ejemplo de la ley general de Costa Rica, cuyo artículo 225.1 dispone que el «órgano deberá conducir el procedimiento con la intención de lograr un máximo de celeridad y eficiencia, dentro del respeto al ordenamiento y a los derechos e intereses del administrado», y su artículo 269.1 precisa que la actuación administrativa se debe realizar «con arreglo a normas de economía, simplicidad, celeridad y eficiencia».

En sentido similar, la ley 19880 de Chile (artículo 7) y la ley de Bolivia (artículo 4n) disponen que conforme al principio de celeridad, la administración debe impulsar el procedimiento «de oficio en todos sus trámites» (artículo 7), lo que en realidad se configura como el principio de oficialidad. Ello implica que en todos los casos en los cuales la administración pueda iniciar de oficio una actuación —si bien es posible y común que el administrado tenga derecho a participar en el procedimiento, por ejemplo, instando a la administración para iniciar su actividad, siendo este, en definitiva, un asunto de esta última-, una vez desencadenado el procedimiento administrativo, el desarrollo y la movilización de este está a cargo de la propia administración, por lo que es a ella a quien le compete $-\mathrm{y}$ no a un tercero- impulsarlo de oficio, 
para la realización de la secuencia de actos que deben concluir con la emisión de un acto administrativo definitivo.

\section{III.9. El principio de eficacia}

El otro clásico principio del procedimiento administrativo que es el principio de eficacia también se define ampliamente en el artículo 4.1.10 de la ley peruana cuando se dice que «los sujetos del procedimiento administrativo deben hacer prevalecer el cumplimiento de la finalidad del acto procedimental, sobre aquellos formalismos cuya realización no incida en su validez, no determinen aspectos importantes en la decisión final, no disminuyan las garantías del procedimiento, ni causen indefensión a los administrados». En todos los supuestos de aplicación de este principio, la finalidad del acto que se privilegie sobre las formalidades no esenciales deberá ajustarse al marco normativo aplicable y su validez será una garantía de la finalidad pública que se busca satisfacer con la aplicación de él.

Este principio de eficacia es recogido también materialmente en todas las leyes de procedimiento administrativo de América Latina, como en las leyes de Argentina (artículo 1), de Venezuela (artículo 30), de Honduras (artículo 19), de Brasil (artículo 2), de México (artículo 13) y en el decreto de Uruguay (artículo 2) .

Conforme a este principio, tal como se lo define en el código colombiano, las autoridades deben buscar «que los procedimientos logren su finalidad,» debiendo, a tal efecto, remover de oficio los obstáculos puramente formales, evitar decisiones inhibitorias, dilaciones o retardos, y deben sanear, de acuerdo con el código, las irregularidades procedimentales que se presenten, en procura de la efectividad del derecho material objeto de la actuación administrativa (artículo 3.11). En consecuencia, ante el no acatamiento de elementos formales en el procedimiento, la administración debe preferir evitar la ineficacia o plantear una ineficacia parcial, antes que concluir con la ineficacia total del acto. Es decir, el procedimiento debe interpretarse de manera que, efectivamente, pueda haber una decisión sin que la falta de cumplimiento de determinadas formalidades afecten el acto y la propia voluntad de la administración.

En el mismo sentido se expresa la ley de Bolivia (artículo 4j), siendo la consecuencia fundamental de este principio, tal como se expresa en la ley de Honduras, que «las cuestiones incidentales que se suscitaren en el procedimiento, incluso las que se refieren a la nulidad de actuaciones no suspenden el curso del mismo» (artículo 39).

5 Véase: BreWER-CARÍAS, Allan. «Los principios de legalidad y eficacia en las leyes de procedimientos administrativos en América Latina». En IV Jornadas Internacionales de Derecho Administrativo "Allan Randolph Brewer-Carías", FUNEDA, 9-12 noviembre de 1998, pp. 21-90, Caracas.

LA REGULACIÓN

DEL

PROCEDIMIENTO

ADMINISTRATIVO

EN AMÉRICA

LATINA

(LEY 27444)

ADMINISTRATIVE

PROCEDURE

REGULATION IN

LATIN AMERICA

(LAW 27444) 
Este principio implica, por otra parte, como se deduce de la fórmula peruana, una vinculación tanto al principio del informalismo como al de la subsanación de defectos no sustanciales y de conservación de los actos administrativos. Es decir, al principio del saneamiento, subsanabilidad y convalidación de los trámites y actos administrativos cuando se trate de irregularidades no esenciales, o, como dice la ley peruana de formalidades, «cuya realización no incida en su validez», precisamente a los efectos de garantizar que los procedimientos puedan lograr su finalidad.

Por ello, por ejemplo, la ley de Honduras establece que cuando un órgano administrativo declare la nulidad de algunas actuaciones debe disponer «siempre la conservación de aquellos actos y trámites cuyo contenido hubiera permanecido, de no haberse realizado la infracción origen de la nulidad» (artículo 39). En igual sentido, se dispone en la ley peruana (artículo 13.3).

Este principio conduce, por supuesto, a la necesidad de la corrección de errores materiales de los actos administrativos, lo que se encuentra regulado expresamente en las leyes de Venezuela (artículo 84), Honduras (artículo 128), Costa Rica (artículo 157) y Chile (artículo 62), «siempre que la enmienda no altere lo sustancial del acto o decisión» (artículo 128), y siempre que, como lo indica la ley del Perú, la rectificación de los errores sea «con efecto retroactivo» (artículo 201.1).

Es precisamente en virtud de este principio de la corrección de errores materiales —que deriva del principio del informalismo, eficacia y de la economía procedimental - que la administración no tiene motivo para concluir con la revocación del acto viciado, ya que puede corregirlo, de oficio o a petición de parte, en cualquier momento. Es un principio de lógica administrativa que, sin embargo, encuentra su expresión formal en las leyes de procedimiento administrativo, incluso en relación con los actos de los administrados. En tal sentido, la ley de Honduras dispone en su artículo 115 que para evitar nulidades, la administración debe señalar a la parte interesada «los defectos de que adolezcan los actos producidos por esta y ordenará que se subsanen de oficio o por el interesado dentro de un plazo de tres días».

Pero aun en presencia de vicios o irregularidades más sustanciales en los actos administrativos, que no puedan resolverse con la sola corrección de errores materiales o aritméticos, el principio conservatio acti exige que los vicios que puedan afectarlos formalmente se subsanen siempre que no conlleven su nulidad absoluta, lo que ha originado las técnicas de convalidación, enmienda, saneamiento o conversión de los actos administrativos que se encuentren regulados en las leyes de procedimiento administrativo — para evitar así su extinción—. 
En particular, conforme a la ley general de Costa Rica, la convalidación se produce cuando, dictado un acto administrativo que sea relativamente nulo por vicio en la forma, en el contenido o en la competencia se dicta un nuevo acto administrativo que lo convalide, con indicación precisa del vicio y de la corrección (artículo 187.2). Sobre esto, la ley venezolana indica, pura y simplemente, que «la Administración podrá convalidar en cualquier momento los actos anulables, subsanando los vicios de que adolezcan» (artículo 81), y, en sentido similar, se regula en la ley de Brasil (artículo 55), en la ley de Bolivia (artículo 37.1), en la ley de Panamá (artículo 56) y en la ley de Honduras (artículo 126). Sin embargo, como se regula en la legislación argentina, «el informalismo no podrá servir para subsanar nulidades que sean absolutas» (artículo 224).

La ley peruana es bien precisa al regular la «enmienda» de los actos administrativos como consecuencia de la «conservación» de los mismos, al precisar que cuando el vicio del acto administrativo por el incumplimiento a sus elementos de validez no sea trascendente «prevalece la conservación del acto, procediéndose a su enmienda por la propia autoridad emisora» (artículo 14.1).

En la legislación argentina, esta convalidación se denomina, en general, «saneamiento» y se desdobla en «ratificación» del acto por el superior jerárquico y «confirmación» por el órgano que dictó el acto (artículo 19).

En esta materia, la ley de Honduras regula, en su artículo 127, la «conversión» del acto, al disponer que «el acto nulo que, sin embargo, contenga todos los requisitos constituidos de otro distinto, podrá ser convertido en este y producirá sus efectos, en su caso, si así lo consintiera el interesado». En este sentido, la ley argentina también señala que «si los elementos válidos de un acto administrativo nulo permitieren integrar otro que fuere válido, podrá efectuarse su conversión en este consintiéndolo el administrado». La misma institución de la conversión se regula en la ley general de Costa Rica (artículo 189).

\section{III.10. El principio de verdad material}

Otro principio importante del procedimiento administrativo definido en la ley peruana es el principio de la verdad material, del que se dice en el artículo 4.1.11 que «en el procedimiento, la autoridad administrativa competente deberá verificar plenamente los hechos que sirven de motivo a sus decisiones, para lo cual deberá adoptar todas las medidas probatorias necesarias autorizadas por la ley, aun cuando no hayan sido propuestas por los administrados o hayan acordado eximirse de ellas».

En el caso de procedimientos trilaterales, la autoridad administrativa estará facultada a verificar por todos los medios disponibles la verdad de los hechos que le son propuestos por las partes, sin que ello signifique

LA REGULACIÓN

DEL

PROCEDIMIENTO

ADMINISTRATIVO

EN AMÉRICA

LATINA

(LEY 27444)

ADMINISTRATIVE

PROCEDURE

REGULATION IN

LATIN AMERICA

(LAW 27444) 
una sustitución del deber probatorio que corresponde a estas. Sin embargo, la autoridad administrativa estará obligada a ejercer dicha facultad cuando su pronunciamiento pudiera involucrar también al interés público.

En otras leyes, como la de Uruguay, el principio de la verdad material solo estaba enunciado (artículo 2), y una definición solo se recogió con posterioridad en la ley de Bolivia de 2002, en la cual, en su artículo 4d, se lo define en el sentido general de que «la Administración Pública investigará la verdad material en oposición a la verdad formal que rige el procedimiento civil».

\section{III.11. El principio de la participación}

Otro principio importante del procedimiento administrativo, también definido en el artículo 4.1.12 de la ley peruana es el principio de la participación. Se dice de él:

1.12. Principio de participación. Las entidades deben brindar las condiciones necesarias a todos los administrados para acceder a la información que administren, sin expresión de causa, salvo aquellas que afectan la intimidad personal, las vinculadas a la seguridad nacional o las que expresamente sean excluidas por ley; y extender las posibilidades de participación de los administrados y de sus representantes, en aquellas decisiones públicas que les puedan afectar, mediante cualquier sistema que permita la difusión, el servicio de acceso a la información y la presentación de opinión.

El principio fue luego incorporado expresamente en la reforma del código colombiano de 2011, sin duda también respondiendo a la orientación general de la Constitución de 1991, donde se disponía que las autoridades deben promover y atender «las iniciativas de los ciudadanos, organizaciones y comunidades encaminadas a intervenir en los procesos de deliberación, formulación, ejecución, control y evaluación de la gestión pública» (artículo 3.6).

Se trata, en todo caso, de un principio definitorio de política pública en el fomento de los mecanismos de participación ciudadana en la gestión pública, el cual, por supuesto, no sustituye, sino complementa, el principio democrático representativo.

\section{III.12. El principio de simplicidad}

El principio de simplicidad también se ha definido en la ley peruana como propio del procedimiento administrativo. En su artículo 4.1.13 se dice de él que «los trámites establecidos por la autoridad administrativa deberán ser sencillos, debiendo eliminarse toda complejidad 
innecesaria; es decir, los requisitos exigidos deberán ser racionales y proporcionales a los fines que se persigue cumplir».

Posteriormente, el principio se recogió en la ley de Bolivia al precisar que «los procedimientos administrativos se desarrollarán con economía, simplicidad y celeridad, evitando la realización de trámites, formalismos o diligencias innecesarias» (artículo 4k), y ha sido, por lo demás, objeto de desarrollo en legislaciones especiales destinadas precisamente al mismo. Por ejemplo, la ley venezolana sobre simplificación de trámites administrativos de 2008 establece sobre este mismo principio, que «el diseño de los trámites administrativos debe realizarse de manera que los mismos sean claros, sencillos ágiles, racionales, pertinentes, útiles y de fácil entendimiento para las personas, a fin de mejorar las relaciones de estos con la Administración Pública, haciendo eficiente y eficaz su actividad».

Por su parte, la Ley Orgánica de Administración Pública de Venezuela, en su artículo 12, dispone que la simplificación de los trámites administrativos será tarea permanente de los órganos y entes de la administración pública, así como la supresión de los que fueren innecesarios. Todo de conformidad con los principios y las normas que establezca la ley correspondiente.

Por ello, estando la administración pública al servicio de los ciudadanos y, en general, de los particulares o administrados, ella debe desarrollar su actividad y organizarse de manera que los particulares, según el artículo 6:

1. Puedan resolver sus asuntos, ser auxiliados en la redacción formal de documentos administrativos, y recibir información de interés general por medios telefónicos, informáticos y telemáticos.

2. Puedan presentar reclamaciones sin el carácter de recursos administrativos, sobre el funcionamiento de la Administración Pública.

3. Puedan acceder fácilmente a información actualizada sobre el esquema de organización de los órganos y entes de la Administración Pública, así como a guías informativas sobre los procedimientos administrativos, servicios y prestaciones que ellos ofrecen.

Además, la Ley de Simplificación de Trámites Administrativos venezolana de 1999 se destinó específicamente a desarrollar en detalle este principio de la simplificación con el objeto de racionalizar las tramitaciones que realizan los particulares ante la administración pública, y de mejorar su eficiencia, pertinencia y utilidad, a fin de lograr mayor celeridad y funcionalidad en las mismas, de reducir los gastos operativos, de obtener ahorros presupuestarios, de cubrir insuficiencias de carácter fiscal y de mejorar las relaciones de la administración pública con los ciudadanos.

LA REGULACIÓN DEL

PROCEDIMIENTO

ADMINISTRATIVO

EN AMÉRICA

LATINA

(LEY 27444)

ADMINISTRATIVE

PROCEDURE

REGULATION IN

LATIN AMERICA

(LAW 27444) 
La ley, además, dispone que la administración pública no puede exigir requisitos adicionales a los contemplados en la normativa vigente, salvo los que se establezcan en los instrumentos normativos que se dicten en ejecución de dicha ley (artículo 10). Con carácter general, además, se dispone que los órganos y entes de la administración pública no pueden exigir para trámite alguno la presentación de copias certificadas actualizadas de partidas de nacimiento, matrimonio o defunción, así como de cualquier otro documento público, salvo los casos expresamente establecidos por ley (artículo 17). Adicionalmente, se dispone que los órganos y entes de la administración pública no pueden exigir copias certificadas de la partida de nacimiento como requisito para el cumplimiento de una determinada tramitación cuando sea presentada la cédula de identidad, salvo los casos expresamente establecidos por ley (artículo 18).

Por otra parte, se dispone que los órganos y entes de la administración pública, en virtud del principio de cooperación que debe imperar en sus relaciones interorgánicas, deben implementar bases de datos automatizadas de fácil acceso y no pueden exigir la presentación de copias certificadas o fotocopias de documentos que la administración pública tenga en su poder, o de los que tenga la posibilidad legal de acceder (artículo 11).

Además, en aras de la simplicidad, la ley agrega que los órganos y entes, en el ámbito de sus competencias, deben eliminar las autorizaciones innecesarias, solicitudes excesivas de información de detalle y, en general, la exigencia de trámites que entorpezcan la actividad administrativa (artículo 13).

Por último, el artículo 14 de la ley dispone en particular que los órganos y entes de la administración deberán identificar y disponer la supresión de los requisitos y permisos no previstos en la ley que limiten o entraben el libre ejercicio de la actividad económica o la iniciativa privada.

Otro principio general derivado de la simplicidad es el principio de la economía procedimental, que se menciona en la generalidad de las leyes de procedimiento, como las leyes de Argentina (artículo 7), de Honduras (artículo 19), de Venezuela (artículo 30), de Uruguay (artículo 2) y de México (artículo 13), y conlleva la necesidad de que los asuntos se decidan administrativamente con celeridad, en la forma más rápida posible, economizando lapsos y al menor costo posible.

El principio ha sido desarrollado ampliamente en la ley 19880 de Chile, en la forma siguiente:

[...] Artículo 9. Principio de economía procedimental. La Administración debe responder a la máxima economía de medios con eficacia, evitando trámites dilatorios. 
Se decidirán en un solo acto todos los trámites que, por su naturaleza, admitan un impulso simultáneo, siempre que no sea obligatorio su cumplimiento sucesivo.

Al solicitar los trámites que deban ser cumplidos por otros órganos, deberá consignarse en la comunicación cursada el plazo establecido al efecto.

Las cuestiones incidentales que se susciten en el procedimiento, incluso las que se refieran a la nulidad de actuaciones, no suspenderán la tramitación del mismo, a menos que la Administración, por resolución fundada, determine lo contrario.

LA REGULACIÓN DEL

PROCEDIMIENTO

ADMINISTRATIVO

EN AMÉRICA

LATINA

(LEY 27444)

ADMINISTRATIVE PROCEDURE

REGULATION IN

LATIN AMERICA

Vinculado a la simplicidad está el principio de la uniformidad, también definido en la ley peruana, en cuyo artículo 4.1 .14 se dice que «la autoridad administrativa deberá establecer requisitos similares para trámites (LAW 27444) similares, garantizando que las excepciones a los principios generales no serán convertidos en la regla general. Toda diferenciación deberá basarse en criterios objetivos debidamente sustentados».

En esta orientación, la Ley Orgánica venezolana establece como obligación general el que «la Administración racionalizará sus sistemas y métodos de trabajo y vigilará su cumplimiento» (artículo 32), y regulará, además, la uniformización de los documentos y expedientes, así como el desarrollo de procedimientos en serie, a efecto de simplificar y racionalizar la actividad (artículo 35). Por su parte, el artículo 7 de la ley de Brasil, expresamente dispone que «los órganos y entidades administrativas deberán elaborar modelos y formularios uniformes para asuntos que impliquen pretensiones equivalentes».

\section{III.14. Los principios de predictibilidad y de privilegio de controles posteriores}

Por último, la ley peruana en sus artículos 4.1 .15 y 4.1 .16 incorporó a su articulado los principios de predictibilidad y de privilegio de controles posteriores, los cuales no encuentran consagración expresa en ninguna de las otras leyes latinoamericanas. Se dice de ellos en la norma peruana lo siguiente:

1.15. Principio de predictibilidad. - La autoridad administrativa deberá brindar a los administrados o sus representantes información veraz, completa y confiable sobre cada trámite, de modo tal que a su inicio, el administrado pueda tener una conciencia bastante certera de cuál será el resultado final que se obtendrá. 
1.16. Principio de privilegio de controles posteriores. - La tramitación de los procedimientos administrativos se sustentará en la aplicación de la fiscalización posterior; reservándose la autoridad administrativa, el derecho de comprobar la veracidad de la información presentada, el cumplimiento de la normatividad sustantiva y aplicar las sanciones pertinentes en caso que la información presentada no sea veraz.

\section{APRECIACIÓN FINAL}

Las leyes de procedimiento administrativo, como la Ley del Procedimiento Administrativo General del Perú (ley 27444), sin duda, tienen un doble carácter.

Por una parte, son un signo de madurez en el desarrollo del Derecho administrativo y en el equilibro que tiene que existir siempre en una sociedad democrática, entre la administración pública y sus poderes y prerrogativas, y los administrados y sus derechos y garantías, de manera que la primera no abuse de aquellos y los segundos no impidan el desarrollo de la actividad administrativa en beneficio del interés general.

Pero, por la otra, son a la vez el instrumento más eficaz para la consolidación del Derecho administrativo, al disponer los jueces en general $-\mathrm{y}$ los de la jurisdicción contencioso administrativa en particular- de textos de Derecho positivo que les faciliten su labor de control, de manera que sus decisiones no solo se fundamenten, como hace décadas, en los principios generales que derivaban de las construcciones doctrinales y jurisprudenciales. Con normas escritas, como las ahora contenidas en todas esta leyes, y, en especial, con la amplitud con que se las concibió en la ley del Perú, la labor de los jueces es más importante para el desarrollo de nuestra disciplina, como se puede apreciar de la jurisprudencia que han sentado en todos nuestros países. 